\title{
Working the Hyphen From Below: The "Thick Decryption of Subtext" and the Micro-Politics of Knowledge Production
}

\section{OPEN ACCESS}

Edited by:

Shaunak Sastry,

University of Cincinnati, United States

Reviewed by:

Leandra Hinojosa Hernandez, Utah Valley University, United States Sonia Rains Ivancic, University of South Florida, United States

*Correspondence: Rebecca de Souza rdesouza@d.umn.edu

Specialty section

This article was submitted to Health Communication,

a section of the journal Frontiers in Communication

Received: 06 May 2019 Accepted: 30 October 2019 Published: 03 December 2019

Citation: de Souza R (2019) Working the Hyphen From Below: The "Thick

Decryption of Subtext" and the

Micro-Politics of Knowledge Production. Front. Commun. 4:68 doi: 10.3389/fcomm.2019.00068

\author{
Rebecca de Souza* \\ Department of Communication, University of Minnesota Duluth, Duluth, MN, United States
}

Engaging in reflexive analysis or "working the Self-Other hyphen" is central to establishing the credibility and trustworthiness of critical qualitative research today. However, while there is a robust literature on how to navigate the Self-Other hyphen, this tends to be written for white scholars going into communities of color. There is very little written by and for scholars of color going into the field to study whiteness. In this paper, I unravel the challenges and complexities of negotiating the Self-Other hyphen as a scholar of color. This manuscript is based solely on a secondary analysis of previously published data. I draw on examples from my own communication research over the past decade in two different settings: HIV and AIDS in India and hunger and food insecurity in the United States. I use peer reviews and reactions from dominant actors in the academy to elucidate how orientalist and white racial frames impact the interpretive, analytical, and writing work of qualitative research. Highlighting the micro-politics of knowledge production, the paper argues that since power operates differently for researchers of color in white spaces, considerations for working the hyphen must also be dramatically altered. The paper offers suggestions for how researchers might maintain a critical, counterhegemonic presence in their research in the face of hegemonic responses.

Keywords: qualitative methods (interviewing), reflexivity, race and class, whiteness and white fragility, social justice, validity

Interviewer: What do you mean like you heard stories?

Xavier: No, it's, it's, okay, I'll tell you this. Okay, in 1979 I became a Muslim, so you know about that? Interviewer: About that?

Xavier: Muslims.

Interviewer: Yeah, I do

Xavier: Okay

Interviewer: I'm from India originally, so I grew up with a lot of Muslim friends and family.

Xavier: Alright, okay. So, anyway now I can feel a little comfortable (emphasis added) because you know a lot of things I say, I say in Arabic, but anyway when I go to the Masjid there's a lot of doctors there, you know and...

Xavier, African American male, Chum client ${ }^{1}$

\footnotetext{
${ }^{1}$ Xavier was one of the $\sim 70$ interviewees who participated in the study on hunger and food insecurity now published in the book Feeding the Other: Whiteness Privilege and Neoliberal Stigma in Food Pantries (de Souza, 2019). Xavier was a frequent client of the Chum food pantry- one of the two food pantries studied in the research project.
} 


\section{INTRODUCTION}

This opening excerpt depicts a brief exchange that took place between a research participant (Xavier) and myself (the interviewer) in a midsize city in Midwestern United States. I, an Indian immigrant, a woman of color, a researcher studying the stigma of hunger and food insecurity in food pantry spaces and my interviewee an African American Muslim man who experiences hunger and food insecurity, racial and religious stigma, and uses the Chum food pantry ${ }^{2}$. In this excerpt, what stood out to me was how cautiously Xavier disclosed his religious identity and then quickly followed it up with a gentle open ended question "you know about that?" At my response, our worlds joined. His face immediately relaxed, he leaned back in the chair, a big smile on his face, and began to talk. As I reflect on this research project spanning a number of years and a number of interactions with people from a variety of racial and class backgrounds, I realize that the moments of connection that I made with people of color were not coincidental. These moments of connection stemmed from my own standpoint, ethical orientation, and phenotypical markers all of which came together to create a safe space for people of color to talk about racism.

Interactions such as these have forced me to reckon with my standpoint as a researcher and how this is hypervisible in the field and in my writing. As a "middle-ground" social researcher and a South Asian woman of color, my critical/feminist/racialized standpoint brings moments of connection, but also intense scrutiny. White social researchers are normalized in research settings, so have far more flexibility in how and even if they carry their voice, body, race, class, or gender into their work. Just the opposite is true for people of color. People of color do not escape scrutiny even when in positions of power as researchers. Our bodies do not disappear in the field or in our texts. Our ideological and political commitments are on full display in how we represent, analyze, interpret, and write about "the data." Indeed, the more clearly we write, the more we are on display. This makes it impossible to fold into the text unnoticed.

The Self-Other hyphen, a term coined by Fine (1994), refers to a longstanding concern in critical qualitative and ethnographic research about the need for reflexivity on the part of researchers, where reflexivity involves "thoughtful, conscious self-awareness" (Finlay, 2002, p. 532). The central idea here is that

\footnotetext{
${ }^{2}$ Chum and Ruby's Pantry were the two food pantries studied as part of the research project on hunger and food insecurity now published in the book Feeding the Other: Whiteness, Privilege, and Neoliberal Stigma in Food Pantries (de Souza, 2019).

${ }^{3}$ I borrow Laura Ellingson's (2009) conceptual framework for qualitative methodology to identify my own proclivities as a qualitative researcher. Ellingson maps the qualitative continuum from a realist/positivist social science stance on the far right, to social constructionist middle ground approaches in the middle, to the artistic interpretive paradigm on the far left. Middle ground approaches involve traditional qualitative/ethnographic research methods (e.g., focus groups, observations, case studies, etc.) and tend to use first person voice, narratives, and interview snippets in the writing and representation of data. Middle ground researchers tend to be interested in situated knowledge, description and understanding, troubling taken-for-granted assumptions, and generating pragmatic implications (see Ellingson, 2009, p. 8-9).
}

identity directly and indirectly influences the research process, so conscious self-awareness is required to understand this influence and increase the integrity, credibility, and trustworthiness of qualitative research. Over the last century, qualitative research has been deeply implicated in colonial, racial, and nationalist projects with the relationship between researcher and the "researched" often mirroring the relationship between oppressors and oppressed. Reflexivity is seen as a way to intervene upon the colonial and neocolonial gaze.

In terms of ability, sexuality, and class, I am on the upper rungs of the hierarchy, but in terms of racial, gender, national and political categories I am nearer the bottom. As a middle class woman of color, a researcher, a Third World woman, and a recent immigrant to the United States marked by color and phenotypical difference, conducting ethnographic research in a predominantly white city in the Midwest and then having it move through a historically white academy, has provided immense opportunity for reflection on the Self-Other hyphen. I started out my academic career studying people living with HIV and AIDS in India and afterwards embarked on a new trajectory of research studying hunger in the United States. While my work has always been reflexive in terms of historical, cultural, and systems thinking, my most recent work on hunger and food insecurity has allowed me to probe a more racially-sensitive reflexivity. This research now published in the book Feeding the Other: Whiteness, Privilege and Neoliberal Stigma in Food Pantries (de Souza, 2019) was interested in food systems and food structures as well as the interactional dynamics of race, class, and gender within food pantries ${ }^{4}$. As the work moved through academic circles, I noticed stark differences in how people received it. It received validation from people of color-participants and non-participants-who saw their truths represented in the work and pulled me aside excitedly to say "yes! I've been wanting to talk about that." Many claims were also validated by white people who for the first time saw verbalized that which was most uncomfortable to them about doling out cheap food. A strenuous challenge however came from whites within academia who took positions of defensiveness and challenged my assertions. These were peer reviewers, students, and other institutional actors who said "But, what about...?" and "But, you didn't..." or just simply said "But, I disagree."

As I attempted to move counterhegemonic assertions through white-dominated academia I experienced subtle forms of suppression that mirrored my social location. Beyond the anticipated labor of making justified arguments through research design, data collection, analysis, and writing, there was a metalevel of labor that had to do with negotiating ideologicallymotivated standpoints, emotions, and pushback from dominant

\footnotetext{
${ }^{4}$ In Feeding the Other (de Souza, 2019) I argue that food pantries stigmatize their clients through a discourse that emphasizes hard work, self-help, and economic productivity rather than food justice and equity- a phenomenon I term "neoliberal stigma". I argue that these "framing, blaming, and shaming" discourses reframe the structural issue of hunger as a problem for the individual hungry person. The book documents the voices, experiences, and realities of people living with hunger; the failure of public institutions to protect citizens from poverty and hunger; the "whiteness" of food pantry volunteers caught between neoliberal and social justice concerns; the culture of suspicion in food pantry spaces; and the constraints on individual food choices.
} 
groups. I was also left in a quandary about how to approach the question of credibility in qualitative research. There were many moments when I second-guessed and doubted my claims, claims that were grounded in the lived experiences and voices of participants at the bottom of the economic and racial hierarchy, but that were contested by dominant actors. There were also times when my thick descriptions of people and perspectives, much to my horror, reinforced hegemonic interpretations among dominant groups. I realized that the standard metrics for establishing credibility had shifted beneath me; the techniques that I had learned within whitened spaces of academia no longer held water.

\section{THE GOAL OF THIS PAPER}

While there are several unwieldy dimensions to the Self-Other phenomenon, in this paper, I put a fine point on one particular aspect, namely how the Self-Other hyphen is negotiated in the interpretive, analytical, and writing work of qualitative research "from below." I use the phrase "from below" to refer to research that makes a preferential option for disenfranchised people from a social justice perspective and seeks to amplify the standpoints of those who are oppressed (Frey et al., 1996). I am particularly interested in how standpoints are negotiated during the reiterative stages of analysis, interpretation, and writing- the point at which knowledge becomes concretized, inscribed in text, and is at the precipice of publication.

The field of critical health communication has engaged deeply with questions of power, language, meanings, ideology, and materiality as expressed in discursive practices; it has also paid attention to western imperialism, global capitalist institutions, colonial and postcolonial relations, and dialectical tensions inherent in discourses of modernization and development (e.g., Dutta-Bergman and de Souza, 2008; Zoller and Dutta, 2008; Rastogi and Dutta, 2015; Sastry and Lovari, 2017). However, much less has been written about the micro-politics of knowledge production. Feminist scholars assert that we must analyze the micro-political processes involved in our research in order to answer questions about the political economy of knowledge production- how is knowledge produced, who produces it, and how does it becomes privileged? (Haraway, 1988; Bhavnani, 1993). It is precisely this underbelly of critical health communication research that I would like to make visible. I draw on examples from my own now published research over the past decade in two different settings: HIV and AIDS in India and hunger and food insecurity in the United States to explore this dilemma. I use double-blind peer reviews from manuscripts submitted over the years as well as open reactions by peer reviewers, reviewers, editors, students, and other institutional actors to show how hegemonic worldviews operate from behind the scenes to shape the writing and presentation of research.

This article makes a practical and theoretical contribution to the field of critical health communication and the broader field of qualitative research methods. The overarching concern of this paper is with the exclusive and privileged nature of communication research and social research more broadly. Race is "one of the most viable and reliable analytical tool for understanding and improving the collective fortunes of people of color in the United States and globally" (Donnor and LadsonBillings, 2018, p. 353). Yet, the barriers put up via formal and informal gatekeeping choke the emancipatory potential of communication. Anthropologist Douglas Foley (2000) ends a rather tortured essay on his own standpoint as a white male researcher studying Mexican American activism stating:

For years I have been hearing tales about how the White maledominated disciplines, professional associations, and publishing game pressure "minority scholars" to be politically correct. Ethnic minority, feminist, and gay and lesbian scholars also need to expose how such pressures compromise their scholarship. It will be good for their souls and for the academy (p. 79).

This paper responds to calls made to expose the more subtle pressures and demands the white academy places on researchers of color and the impact it has on our work and us. Theoretically, this article makes a contribution to qualitative research methods by unmasking and refining what it means to "work the hyphen" as a scholar of color. Once we trouble the assumption that all researchers speak from positions of power and that academia is a neutral non-ideological unraced space, then "working the hyphen" takes on new meaning. Because power operates differently researchers of color in white spaces, reflexivity for these researchers must look very different from the "thoughtful self-consciousness" of white researchers. This has implications for the credibility of our work and how it is evaluated.

\section{UNMASKING THE SELF-OTHER DICHOTOMY}

While there is a robust literature on reflexivity and how to navigate the Self-Other hyphen, much of it is written by and for white people going into communities of color. Even as this literature draws on the work of Black and Third World feminists (e.g., Mohanty, 1993), an unfortunate blind spot in this very progressive literature is that people who do research are white, while people being studied are "Other." Fine (1994) writes that the "Self and Other are knottily entangled" in the research process making it critical for qualitative researchers to locate themselves in the research process (p. 72). "Working the hyphen" is a way to resist the imperializing gaze of western Christianity and manage tensions with outsider (etic) approaches to culture, where the ethnographer and the "observed" hold different values. Fine (1994) carefully observes:

When we opt, as has been the tradition, simply to write about those who have been Othered, we deny the hyphen. Slipping into a contradictory discourse of individualism, personalogic theorizing, and decontextualization, we inscribe the Other, strain to white out Self, and refuse to engage the contradictions that litter our texts. When we opt, instead, to engage in social struggles with those who have been exploited and subjugated, we work the hyphen, revealing far more about ourselves, and far more about the structures of Othering (p. 72). 
There are several useful directives and guidelines for qualitative researchers going into "Other" spaces. To prevent reinforcing stigmatizing frames, researchers are asked to "write against othering" by interrogating their own standpoints and positionalities in the world. The literature cautions researchers to be mindful of their personal and social privilege, to strive for increased transparency, to describe context "thickly," to give participants voice, to connect the stories of individuals to historic, structural, and economic relations in which they are situated, and "to do no harm" (Fine, 1994; Fine et al., 2003). Best practices also include not withholding crucial information and knowledge from research participants, an increased openness with participants about the goals of the research, allowing research participants to shape research questions and have "voice" in the data (Hurtado and Stewart, 1997). While researchers are not necessarily asked to kowtow to participant interpretations, qualitative researchers are directed to describe contexts thickly, show multiple perspectives, show richness and contradiction, and allow readers to draw their own interpretations about meanings and significance (Patton, 2002; Ellingson, 2009; Denzin and Lincoln, 2018).

In the course of my research, I found myself scouring through the literature looking for guidance on how to navigate my own racial unevenness in the research process as a person of color navigating white-dominated spaces. The established guidelines made sense some of the time, but not all of the time. Reflexivity surrounding race and class were addressed in the literature, but the researcher was assumed to belong to the racially dominant group. The question of whether or not to share the emerging analysis and interpretation of data with dominant actors- and how to do so- was also left unanswered. When is it appropriate and in what settings is it appropriate to share such an analysis with powerful stakeholders? As a woman of color conducting research in white spaces what are the added challenges of doing so? In addition, the micropolitics of research, particularly the meta-labor of tiptoeing around the ideological stances of academic actors were usually not addressed.

There were only a few scholars who discussed the issues that I was grappling with. For instance, Hurtado and Stewart (1997) noted that while feminist epistemology had developed methods, guidelines, and "best practices" to affirm the marginalized perspectives of participants, but the same question had not been answered in the study of whiteness. "How do these suggestions, flowing as they do from a concern about the power imbalance between researcher and the researched, fare when we turn to research on whiteness?" (p. 307). They note that recording and repeating racist views of participants only reifies racism in an already racist society. So instead, they argue for maintaining a "critical, counterhegemonic presence" in the research: "When exploring hegemonic experiences like whiteness, the trick is to find ways to retain a critical, counterhegemonic presence in the research" (p. 309-310). Furthermore, they point out that "thick" description or "giving voice" must give way to "thick" analysis and holding ourselves and others to "a very high standard of analytic depth" when work carries a risk of causing suffering in those already the objects of daily racism (p. 307).
Feminist and critical race scholar Bhavnani (1993) similarly pointed out how feminist epistemology had erased, denied, ignored or tokenized contradictory and conflicting interests and standpoints of women from all around the world. A key question she posed was: "how and to what extent does the research conduct, write-up, and dissemination deal with the micropolitics of the research encounter- what are the relationships of domination and subordination which the researcher has negotiated and what are the means through which they are discussed in the research report?" (p. 98). She analyzed her own interviews with young white working class people in Britain and found an unevenness on both sides; her racialized and gendered ascriptions suggested that both structural dominance and subordination were in play for herself and her interviewees. She writes: "What I am suggesting is that an inversion of this "normal" power imbalance in research studiesfrom the conception right through to the analysis- can permit a sharper analysis of the micropolitics of research, so that feminist objectivity can be implemented. So, any text which emerges in a research encounter cannot be taken for granted (p. 102)."

The work of sociologist Bonilla-Silva (2010) on color-blind racism also provided a way forward through methodological terrain fraught with struggle particularly with regard to analysis and interpretation. He noted, as many do, that interpretations are always infallible and neither the researcher nor their potential critics hold a monopoly over the right way of interpreting data. But then he added this statement, which for me captured the tension I was experiencing and helped make the path less foggy. "All of us try our best to construct robust explanations of events and hope that in the tilted market of ideas (tilted toward interpretations of the powerful) the most plausible ones achieve legitimacy" (p. 14, emphasis added). As to the burning question of trustworthiness and credibility of his own research, which had clear theoretical and political orientations, he wrote: "Judge my cartographic effort of drawing the boundaries of contemporary white racial ideology in terms of its usefulness (Does it help to better understand whites' views?), accuracy (Does it accurately depict whites' arguments about racial matters?), details (Does it highlight elements of whites' collective representation not discussed by others?), and clarity (Does it ultimately help you move from here to there)" (p. 15). In my analysis of whiteness in food pantry settings, these criteria became far more valuable to me than engaging in direct debate and argumentation with particular research participants or groups and/or attempting to achieve consensus around interpretations. That would come later perhaps, but for now the dynamics of power and subjugation in the research setting were far too uneven on all sides. Instead I focused on these questions: Is my work useful, descriptive and detailed, and does it help us move from here to there? "There" being a vision of food and social justice. I shared the emerging analysis informally with broader groups of people from dominant and non-dominant social locations and in and out of food pantry settings. The feedback and reactions were useful for both supporting the analysis and ascertaining counterinterpretations and viewpoints. I also observed that since I was swimming in white-dominated culture, accessing hegemonic arguments was relatively easy. These viewpoints were neither 
invisible nor absent. They constantly exerted pressure on me to shift the analysis. In fact, maintaining a counterhegemonic presence in the face of these dominant forces was no easy task. So in going about my work, I attempted to address all the counter viewpoints in the writing itself while struggling to maintain and "own" my position. This was not a linear process and involved a great deal of emotional, intellectual, and embodied effort.

In what follows, I provide three examples from my own research on HIV and AIDS in India and hunger in the US to illuminate how the micro-politics of research and powerinversions shaped my writing and the production of knowledge.

\section{"THICK DESCRIPTION" OR "PRIMITIVE FACTS"?}

A standard metric for evaluating the credibility of ethnographic research is "thick description"-a technique advanced by anthropologist Geertz (1994) as a way to move from a more scientific style of writing up the data to a more literary style showcasing local wisdom and in situ knowledge. What makes an ethnographic description "thick" is not that it mirrors true reality but that it holds "intelligent, richly detailed, locally significant, and intricate accounts constructed by the ethnographer" (Chen and Pearce, 1995, p. 144). Geertz (1994) noted famously "the value of an ethnographic account does not rest on its author's ability to capture primitive facts ... but on the degree to which he is able to clarify what goes on in such places, to reduce the puzzlement" and "to sort out the winks from twitches and real winks from mimicked ones" (p. 222). For Geertz, the ability to show distinctions and deeper meanings behind interactions was at the heart of "thick description," not necessarily a focus on descriptive details for their own value. However, this is not always what counts for thick description in a historically white academic context.

Given that ethnographic work came about as a way to know the Other and is still used for those ends, thick description is often simply a way to capture primitive facts, rather than identify deep distinctions. Rather than a means of "writing against othering," thick description becomes a way to compensate for that which the audience does not recognize about the Other, and in so doing puts the Other on display. Fine (1994) writes:

The imperialism of such scholarship is evident in terms of those whose lives get displayed and whose lives get protected by social science. Put another way, why don't we know much about how the rich live? Why don't we study whiteness? How do "their" and "our" lives get investigated (and not)? Whose stories are presented as if "naturally" self-revealing and whose stories are surrounded by "compensatory" theory? (p. 73).

As I reflect on my work on HIV and AIDS in India, I realize how seemingly benign requests for "more context" from peer reviewers functioned as a mode of imperialism in my work. As a researcher studying "my" people in India, every article I submitted for peer review came back with demands for more descriptive details. I recognize now that I was disadvantaged because what was taken-for-granted in my mind needed to be described in great detail for a predominantly white western academic audience and peer reviewers. In every case, reviewers made demands for primitive facts and even generalizations, stereotypes, and frames that would be familiar to their own racial cognitive schemas as seen here:

Page 20, I am just curious as it makes it sound like widows of HIV patients are outcasted but isn't common in many parts of India for widows to be outcasted? Perhaps, this population faces additional challenges and difficulties (though the author does bring this point out later in the section) but again the discussion ought to be located in power for/in empowerment where the author notes "family are provided with communicative platforms \& skills" (i.e. trained for power-with).

Here is another example from a different article on the role of biomedicine in the lives of people living with HIV and AIDS:

The analysis of how the Western biomedical paradigm displaces and/or is re-articulated as "folk" knowledge is intriguing. However, it would be useful to provide some context as to how this process occurs. For instance, what are traditional "folk" definitions of disease in India and how do they compare to those offered by biomedicine?

These requests for compare and contrast type analytical frameworks juxtaposing tradition with modernity occurred with great frequency in my manuscripts. Even as my own article attempted to interrogate orientalist assumptions underlying the use of the term "folk" in discussing meanings of medicine, I was being asked to make a distinction between the two. Reflecting on these interactions, I realize that the purpose of requesting these descriptive details was to allow the Other to fit within dominant cognitive schemas-in this case orientalist and "white racial frames" (Feagin, 2013)- and doing so in fact increased the credibility of the research in this particular venue.

The next example shows how white racial frames operate from behind the scenes to shape the writing of the research. Here my peer reviewer commented about their lack of contextual understanding surrounding commercial sex workers (CSWs) in Bangalore India. These were sex workers who were being organized by a local non-government organization called SPAN for HIV prevention and support.

Later (pg. 18), Geeta's dialogue indicates that a madam is part of SPAN (and wow does that need to be explained) and that it was this Madam that initiated the formation of Sangha [organization]. I have to be honest, I clearly don't understand the culture and my very ethnocentric understanding of prostitution is largely a function of Western media like Law and Order: Special Victims Unit or the Madam with the heart 'o gold in "Best Little Whorehouse in Texas." So, in addition to clarifying just how SPAN helps these women, you need to help readers understand the social and political context of sex work in India.

I remember how sick I felt on reading this particular comment. I had a visceral embodied reaction. I was disturbed that this reviewer had compared women in India living with HIV at the bottom of every rung of every social structure to Hollywood 
productions- and quite flippantly at that. As an avid consumer of Law and Order SVU myself, I had never made that connection. It did not occur to me that anyone would make that connectionand dare to speak it into being. As a researcher, I was troubled because I thought I had done enough to contextualize this group of Indian women already. The paper already talked about the abuse the women experienced in the hands of police, pimps, and clients, what more was required really? In retrospect, this comment was typical of how the directive for thick description is often employed to capture primitive facts. This was not thick description that showed the difference between the twitches and winks that Geertz talked about, but here broad brush strokes had come to stand in for thick description. In the end, I deleted excerpts from the interviews and replaced them with about five hundred words describing in somewhat static terms the social location of my participants.

This reviewer's comment was a defining moment in my career as a critical communication scholar. In this moment, as an untenured assistant professor, I was very swiftly made aware of the immense social distance between us: the reviewer and a very white discipline of communication on the one hand and myself and my participants on the other. The Self and Other were awkwardly merged and articulated in these pieces of writing. I was placed in an odd position of being both Self and Other and both insider and an outsider. I was a member of the group under study and of the elite research community. I was an outsider to the group I was studying and an outsider of the elite research community. I was the writer, but there were several other writers who were shaping my writing from behind the scenes. So many times I simplified, generalized, and fit information into recognizable western cognitive schemas. In so doing, one could argue that my research had become a cavern for a more subtle kind of imperialism where the Other was put on display for an elite academic community. In these articles, the stories of the women and men that I talked to could not be made to appear normal, but were Otherized by an orientalist fetish. My participants had their lives displayed, I had my commitments displayed as a researcher and a brown woman, but the white academic institution operating in the background and from the sidelines, remained hidden and unexposed in the text.

\section{CHALLENGING THE "THICK DECRYPTION OF SUBTEXT"}

In my more recent work on hunger and food insecurity in the United States, which explored the operation of race in food pantries, I faced a slightly different challenge with regard to thick description of context. In a "racism gone under" context, racism has quite literally gone under making it a challenge to study. In color blind post-racial contexts, traditional instruments like surveys and interviews with direct questions about racial attitudes and actions are not able to identify racial issuesthey do not uncover the variety of ways in which racism expresses itself (Bonilla-Silva, 2010). For instance, although not explicit, race is typically the subject just beneath the surface of terms such as welfare, urban, crime, and poverty, which are terms used strategically to evoke people of color (Gilens, 1999). Winant (1997) points out that since the 1960s racial discourse has been unable to function as a logic for racial superiority and justified exclusion. "Therefore it has been forced into rearticulations, rerepresentations, reinterpretations of the meaning of race and, perforce, of whiteness" (p. 40). This means that our methods must be able to identify and make visible these rearticulations, rerepresentations, and reinterpretations. Hurtado and Stewart (1997) talk about the need to move beyond thick description to thick analysis and "a very high standard of analytic depth" in these situations (p. 307). Wellman (1993) and Frankenberg (1993) write about the importance of using rich layered sociohistories to reveal the subtleties and complexities of racism, beyond the most obvious kinds.

Since racism is often concealed in text, structures, policies, and environments, in my work I have found that I also need to thickly describe and analyze not just what is visible, but what is invisiblethe subtext and "absent presences." The "presence of an absence" may be thought of as the figurative presence of race and racism, even in the virtual absence of people of color (Rosenberg, 1997, p. 80). Uncovering absent presences requires excavating beneath discursive practices for ideological assumptions and orientations. I refer to all of this deep analytical work as the "thick decryption of subtext" as opposed to the "thick description of context." For researchers using middle-ground qualitative approaches and with healthy commitments to empirical evidence, accounting for absence requires detailed work. Since the evidence is no longer about what is observable by its presence, but what is observable by absence, a challenge is posed to credibility. For instance, in the case of Chum $^{5}$, one of the more liberal food pantries that I studied, I made the argument that even though public relations materials identified economic factors that brought people to food pantries, there were discursive erasures with regard to historical and contemporary patterns of racial inequities. The public relations materials went out of their way to speak around racism. Explicit language about the problem of racial inequity was absent, although present were several images of people of color who were being helped by Chum's work. In light of this evidence and more, I argued that even though racial inequity remained unarticulated, there was a racial subtext to the discourse.

In another example from Ruby's Pantry, the more conservative food pantry that I studied, I described a letter written by Lyn Sahr, the pastor and founder of the pop-up food pantry network. In his letter, Sahr used a Bible verse to draw the connection between laziness and material poverty: "A little sleep, a little slumber, a little folding of the hands to rest-and poverty will come on you like a bandit" (Proverbs 6:10-11). In Sahr's interpretation, it was not structural or historical factors that created poverty, but rather the "poverty bandit." The text had embedded within it an image

\footnotetext{
${ }^{5}$ This research study was based on a comparative case analysis of two food pantries in Duluth, Minnesota: Chum and Ruby's Pantry. The pantries varied in religious and political orientation, organizational structure, quantity and quality of food distributed, clientele, and relationship to the state. Chum is a politically liberal organization, uses a social justice lens in its work, and receives government funding. RP on the other hand is rooted in evangelical conservative leanings, makes no claims about social justice, and positions itself in opposition to government programs.
} 
of a Black man-the paradigmatic racial Other- with a shaved head. The man is holding his head in his hands and leaning over a desk, with one arm extended into a clenched fist because presumably the poverty bandit had stolen his dignity. It is one of only three images found across the sample of Sahr's letters. Here too I similarly made the argument that even though there was no direct racism in the letter, the underlying interpretive context for this message was anti-Black racism. I made the claim because of the text of the letter itself, the imagery that accompanied the letter, the larger context of Sahr's letters, and the extant literature that has started to decode rearticulations, rerepresentations, and reinterpretations of racism.

However, in these instances, the lack of explicit racism in the texts combined with my thick decryption opened the door for dominant actors to contest the claim. In highly engaged discussions ${ }^{6}$, my white students called into question the credibility of my claims using the language of "coincidence"- well perhaps it was just a coincidence that these pictures were chosen and maybe it did not mean much that they were embedded in the text. Perhaps they were just "stock images." Sahr sounded like a good man helping others, but here I was putting the pieces together in a different way that cast a shadow. A defining moment in my own reflexive journey occurred when one student started to grill me: "Do you think Sahr is a racist? Is he a racist? What do you think?" This caught me off guard. Everything within me began to scream. I thought I had laid the evidence out so clearly. Wasn't this so obvious? Was it me or him- my student? Maybe I had managed to hide myself amid the analytical depth. Did this white male student, a self-identified liberal want some kind of odd closure? Did he want me to say the word "racist" so it would resolve something in his mind? To his disappointment, I did not answer the question. Instead I told the class that the goal of my research was not to hunt out individual racists - a phrase borrowed from Bonilla-Silva (2010), but to unpack deep-seated ideas that upheld systemic racism. But they were of course free to identify racists based on their own discernment of the evidence. Another student piped up "I think Sahr is a good man, he just wants to help out."

The reactions of my students informed the writing of my research in that I painstakingly rewrote each chapter of the book to respond to such hegemonic stipulations and to clarify my own standpoint. The analysis, much to my horror, had left too much room for interpretation. The methodological directive to describe thickly and allow people to draw their own interpretations about meanings (e.g., Patton, 2002) was flawed in this context. The invitation to see nuance and subtext had been received by my

\footnotetext{
${ }^{6}$ The class conversations depicted in this paper came from the course titled "The Politics of Food, Health, and Communication" - a required senior capstone seminar for communication undergraduate majors. The course content centers on the research interests of individual faculty members. The course format is akin to a graduate-level course with small class sizes and a focus on reading, discussion, and peer teaching and learning. While a requirement, students choose from among 3-5 different courses each semester led by different faculty. In my course, I spend much time building rapport with students and creating a safe space for reflection, discussion, and argumentation. Student evaluations confirm that students experience the course in this way and appreciate the opportunity for frank conversation.
}

readers as an invitation to maintain hegemony. In this instance, working the hyphen meant recognizing that my work was indeed ideological (as all research is), but that this ideology had life and death consequences for people of color. In addition to the names, faces, and voices of my participants like Xavier, Antoine, Gabrielle, and Trinity, I could not stop another litany of names scrolling through my head: Eric Garner, Michael Brown, Jamar Clark, Tamir Rice, Freddie Gray, Stephon Clark, Alton Sterling, Philando Castile ... This was the historical moment I was writing within and I did not ever want my readers to doubt where I stood. So I used my authorial privilege to revise the book. My goal was to provide enough description so people could interpret the data for themselves, but to also be clear about what $I$ as the researcher thought the data revealed. I did this by using a series of questions to acknowledge the viewpoints of dominant actors followed by unequivocal concluding statements-a final word so to speak. In this particular instance of the Black man and the "poverty bandit," I ended with this statement.

All in all, this text now joins the deluge of discourses circulating in society that reinforce age-old racist assumptions and stereotypes about people of color being poor and lazy, while absolving the roles of capitalism, structural racism, and a whitened Christianity in producing racial disparities.

When I read this statement now, it sounds easy and the writing even flows. But I wrote and rewrote this statement a hundred times. I remember the clicking and clacking sounds of the keyboard interrupted by silence calling to mind the profane and sacred wisdom of Gloria Anzaldúa:

Write with your eyes like painters, with your ears like musicians, with your feet like dancers. You are the truthsayer with quill and torch. Write with your tongues of fire. Don't let the pen banish you from yourself. Don't let the ink coagulate in your pens. Don't let the censor snuff out the spark, nor the gags muffle your voice. Put your shit on the paper (Anzaldúa, 2015, p. 171).

\section{WHITE FRAGILITY IN ACADEMIC SPACES}

To have white privilege is to always be surrounded by pro-white meanings, analytical frames, and interpretations, so when claims, assertions, and conclusions are offered that do not employ a prowhite bias, the result is racial defensiveness. White fragility is defined as:

\footnotetext{
a state in which even a minimum amount of racial stress becomes intolerable, triggering a range of defensive moves. These moves include the outward display of emotions such as anger, fear, and guilt, and behaviors such as argumentation, silence, and leaving the stress-inducing situation. These behaviors, in turn, function to reinstate white racial equilibrium (DiAngelo, 2011, p. 54).
}

A key burden that scholars of color face in writing about whiteness in a white academy is that whites do not know themselves as a group. Whiteness is not an empty cultural space, but a social location and a way of life lived in separation from the Other (e.g., Kobayashi and Peake, 2000). However, until recently 
whites have not had a way to understand the psychological meaning of their race and the material implications of being raced (Carter, 1997). One way the lack of conscious awareness is expressed is in resistance to critiques of whiteness and opposition to even a most neutral analyses of whiteness that does not include a pro-white bias. Indeed, similar to Hurtado and Stewart (1997), I have learned in the course of my research that: "although few can articulate the privileges that whiteness brings, most can detect when whiteness is being questioned and its privilege potentially dismantled" (p. 303).

In my research on hunger, I observed that most white people showed little stress or discomfort talking about racism and racial inequities in general, but when the lens shifted to focus on whiteness there was discomfort. I received no challenges to my analysis so long as it fit within the cognitive schemas of dominant actors. The topics of oppressed Black and brown people, poor neighborhoods, and food deserts were tolerable. Indeed, there was empathy for the Other- American Indian and African American clients of food pantries. I described the context of people's lives, the reasons they came to the food pantry, the stressors they lived with, and the aspirations they carried. I connected the stories of individuals to historic, structural, and economic relations in which they were situated including Jim Crow and the genocide of indigenous communities. White institutional actors who read the chapter responded in normatively appropriate ways-they showed empathy, shook their heads in disgust at the stories of abuse, and accepted the historical evidence.

However, all of this changed when I shifted the lens to make claims about whiteness honing in on the interactions between white food pantry volunteers and Black and brown clients. In my work, the most fragile responses came from reviewers, editors, and undergraduate students who read versions of the book chapters. In one of the chapters, I wrote about Lisa, a long-term volunteer at the Chum food shelf, who brought her daughter to the food shelf to teach her that the clients are "no different" from her. To demonstrate whiteness, its motivations, and structural privilege, I wrote about how Lisa gives to charity, but also how her life is lived in complete separation from the Other.

Her family lives in a rich neighborhood, all their friends are wealthy, and her daughter goes to the best school in the city. Volunteering at Chum is a way to expose her daughter to people who are not wealthy and do not live like they do. The pedagogical goal is to show her daughter that They are just like Us and that moving between one "category or camp" and another is simply a matter of employment and who gets to keep their jobs.

I used this set-up to assert that neoliberal stigma is reinforced through color blind articulations that do not engage with the deep histories and political contexts of people of color.

I had three sets of senior undergraduate students over 3years read drafts of this chapter finally titled The "Good White Women" at the Chum Food Shelf. The conversations, the remarks, the resistance, the gut-wrenching honesty, and the one white female student who between broken sobs said to her classmates, while avoiding glancing in my direction, “you know, how they're saying those good white women, you know they're just, you know, they're just nice women." In this instance, completely unaccustomed to seeing white women grouped together in a particular racial formation complete with cultural patterns and behaviors, the student's racial comfort was disturbed. As a Third World woman of color, who has had many things said about her, I could empathize. Indeed, more than a few white students thought I was making unfair claims about Lisa. Some thought that it would not have not been age appropriate for Lisa to talk to her daughter about such things. Many were honest and said that they too would have possibly explained the food pantry in that way. They wanted me to affirm that I was not calling her a racist- which I was not. I was making a point about whiteness. Lisa is not necessarily anti-Black, but rather she is incredibly white, not in an essentialist way but because of the connection between "privilege property, and paler skin" (Slocum, 2007, p. 521). Lisa was an active participant in the system of whiteness, thereby contributing the systemic oppression of the Other.

Since whiteness is rarely scrutinized, any attempt to examine it results in fragile responses. People of color have typically been the targets, objects, and subjects of investigations, while white people (and whiteness) have been construed as normal, normative, and unproblematic. Fine et al. (2003) write:

Across the social sciences, scholarship has fetishized "people of color" as the "problem to be understood" to the extent that whiteness, in all its glistening privilege has evaporated beyond study. One of the ironies of white power is the ability to escape social and intellectual surveillance (p. ix).

Putting whiteness under scrutiny is unsettling because it creates uncertainty; the project is no longer about hunting out individual racists, but about putting white culture in all its "glistening privilege" under the microscope. For white folks who have not yet committed to the project of anti-racism, it makes them feel distanced and different. The study of whiteness produces cognitive dissonance with regard to identity- there is a lag between how they perceive their behaviors and my interpretation of those behaviors. In fact, most have never thought of themselves as even belonging to a racial group! This leads to emotions ranging from anger to defensiveness to sadness. In light of these fragile responses, I rewrote the chapter many times using the same technique: a series of questions acknowledging dominant views and concerns followed by analyses and statements to maintain a counterhegemonic presence in the research. For instance:

Is Lisa ignorant? Is Lisa a racist? Does she think her daughter is too young to understand racial issues? Is she being politically correct? There are many ways to rationalize Lisa's discourse, but even so we must at least recognize two key points. First, Lisa speaks from a racialized position of whiteness....

I coupled these questions and attributions with the concluding statement:

Even as communities of color prepare their 3- and 4-year-olds for the white terror that will be unleashed upon their bodies, Lisa's daughter is spared an education in systemic racism because it does not affect her. 
It is not easy to maintain a counterhegemonic presence because challenges can come from anywhere, anytime, and when you least expect it. The next example from the same chapter depicts one such struggle. This comment came from one of the many editors who went through the book with a fine-toothed comb; she caught typos, analytical errors, and missing evidence and I was very grateful and impressed by her thorough work. In this chapter I described Penny, a white female volunteer at a local food pantry, who talked at length about how she had been called a racist by a Black female client. Penny started out her description of the event saying "Well, there was actually one client, a lady in particular who was a little more prickly. ..." In my original manuscript, I started with this assertion.

Significantly, Penny starts out the story without identifying the lady as African-American, but by using the racially coded term "prickly lady" we already know the race of the client, because it is a term laden with ideological formations surrounding Black female aggression.

The analysis then moved on to unpack the episode through the lens of white fragility (Penny's fragility) and racial stigma. I thought I had done enough to substantiate my reasons for asserting that "prickly" was a racially loaded term. Since stigma and stereotypes were the subject of the book, I had outlined these conceptual themes quite thoroughly in the first two chapters of the book. However, the editor made this comment regarding my assertion.

Just curious-is this something there's actual research on? I for one wouldn't assume anything race-related based on that term; to be honest, it makes me think instead immediately of my grandmother on my father's side, who was pretty decidedly white. Heck, I've been known to describe myself as being in a prickly mood when I'm feeling irritable.

My immediate reaction to this comment was visceral. I felt anger rise within me. I had spent no less than three years working and reworking this one single chapter about whiteness in response to white fragility. More importantly, I had just spent the last three chapters arguing for how we should listen to the voices of the hungry and not argue with them from our privileged standpoints. In fact, the previous chapter documented in great detail the voices of food pantry clients. The editor might have simply asked me to unpack my assertion more, but tellingly she asked for proof. Is there actual research on this? I wondered if white researchers writing about people in India or about people of color in the United States had their claims checked in this way. I have heard from colleagues about how they get so "angry and mad" with negative peer reviews, that they have stacks of articles that have never been revised. As a woman of color, a nonresident alien and then an immigrant, this kind of walking away has never been in my knapsack of privileges. I spent the next few deeply disturbed days reflecting and being reflexive about how I knew what I knew and why she the editor had said what she said. In doing so, I realized a few things: what I took to be a basic even primitive fact was for her an opinion that needed substantiation. I knew the racial code, but she did not. I was an expert by experience and training and that's how I knew the racial code. My editor as a white woman had identified with Penny. She knew her, she recognized herself in her and understood her, and so my assertion came up short. My editor related more deeply with Penny than to me or the Black woman in the story. Furthermore, she interpreted our difference of opinion to be just that- a benign difference of opinion. She did so because like Penny, she had disconnected the interaction from deeper historical, structural, and economic relations. The empathy produced by the previous chapters- which had put on display the struggles of food pantry clients- had quickly evaporated. In an instant, we had hit the very same wall of whiteness. Yet again here was another white woman with the very best of intentions attempting to reshape and redirect the equitable production of knowledge.

It took a few days for me to stamp out my anger and then a few more to recognize my own power. In this setting, I was no longer the untenured faculty seeking to build a publication record. The manuscript had already been accepted by one of the top presses in the country and was about to go to print. It would be published whether or not I chose to respond to the editor's claim. But I also realized that if my editor, a smart cogent selfidentified liberal white woman (she had mentioned her political leanings in an earlier comment), did not trust the assertion of mine, there was a big chance that the claim would lack credibility with other whites as well. This credibility was important to me given the social justice imperative of the research. I was writing this book for people in positions of power, specifically good whites engaged in "ending hunger," with the hope that they would see their charity in a new light. I realized that a higher standard of analytic depth was required to unpack the "rearticulations, rerepresentations, reinterpretations of the meaning of race and, perforce, or whiteness" (Winant, 1997, p. 40).

So I then switched into survival mode, set my face to stone, and dug in. I was incredibly relieved to find Black feminist and legal scholars who had done the intellectual work of studying the "angry black woman" (ABW) stereotype (e.g., Walley-Jean, 2009; Jones and Norwood, 2017). I wondered what barriers they faced in bringing these works to publication. I used their work to substantiate my claim and to provide an even stronger counterhegemonic presence in the research. So after what seemed like a lifetime had passed, I responded to the comment made by the editor in this way:

\footnotetext{
Yes! Tons of research on "the angry black woman" stereotype- and the language codes and manner of interaction. Prickly is benign when whites use it for themselves or other white people, but it is problematic in interracial contexts- especially like these. Context is key here. Your question/comment was an important one- and I realized I needed to add more here in terms of citations and contextualizing. I have done so- so it has changed a bit from the original. These are the three pieces newly cited here. The law review is a really good article- in case you are wanting to read about it.
}

Similar to the literature that I had just cited on the ABW stereotype, my response to the editor was prosaic, professional, 
and wiped clean of anger, pain, and struggle. I retained my initial assertion in the book, but added about 200 words citing three hefty publications including a law review. I revised my original assertions to now read in this way:

However, in her use of the term prickly lady, I was already primed for the race of the client, because in this context, the term prickly fit precisely within the trope of the "Angry Black Woman" $(\mathrm{ABW}) \ldots$

\section{CONCLUDING COMMENTS AND RECOMMENDATIONS}

It is important for scholars of color to debunk assumptions, including our own, that academic spaces are neutral, nonideological, and un-raced. In my own work, I have learned that navigating the Self-Other hyphen means recognizing that "thick description" when interpreted merely as description of primitive facts can function as a mode of imperialism in the research. I have also learned that when studying whiteness, the worldviews of gatekeepers can function to suppress the voices of participants of color and my own voice. As scholars of color, we have a whole host of power similar to white researchers in that we ask questions, present and represent participants, and engage in the analytical work to make sense of findings; however, we are also disempowered in academia when advancing counterhegemonic claims. People of color whether as researchers or writers are often undermined as producers of knowledge (Collins, 1990; Mohanty, 1993; Anzaldúa, 2015). This suppression harms our careers, our mental and emotional well-being, and is an unseen impediment to the construction of knowledge. Cook (1997) argues that white dominance in academia is both about demographics and dominant value systems.

One obvious reason for identifying academia as "White" is that in many instances in predominantly White colleges and universities, the academic departments consist of a resounding majority of White faculty members. Thus, the demographics create an environment of "Whiteness." Perhaps less obvious is that the value systems upon which academic departments routinely function reflect the values of Western European, or White American cultural values. Furthermore, cultural racism within White academia is such that the White cultural values are strictly enforced and built into the power structure of academic departments (p. 101).

When scholars of color go into the field to interview, to observe, and put forth assertions about people in dominant and nondominant locations, the implications and considerations for working the hyphen are dramatically altered. To overlook this kind of role reversal between the Self and Other is to reinforce a "one size fits all" measure of validity in qualitative work that fails to account for the intersectional identities of researchers and the interflows of power that shape the construction of knowledge. That said, the Self-Other hyphen also provides an appropriate conceptual framework in which to boldly make visible our bodies, our writing, and our struggles with power-and in so doing enhance the credibility of our work and dismantle an inequitable political economy of knowledge production. To this end, I offer a few practical recommendations for navigating the hyphen from below and establishing criteria by which our work can be evaluated.

First, we must write openly and explicitly in our texts about the ways in which hegemonic forces have shaped our research. As researchers, we are adept at discussing our privilege in the "reflexivity" sections of our manuscripts, but less so at naming our marginalization. This is not a call to overstate our powerlessness, because indeed we are privileged in many ways, but to also not understate our marginality. This is also not a call to saturate our texts with narcissistic reflections, but a call for more transparency in how our works are produced and co-produced. In her work on crystallization, Ellingson (2009) writes that reflexive consideration of the researcher's self in the process of research design, collection, and representation may be incorporated in an appendix, footnotes or endnotes, interludes or even a separate cross referenced or linked text. For scholars of color, these notes and interludes must also include ways in which academic gatekeeping has functioned in our work either by suppressing counterhegemonic claims or by allowing voices from below to flow freely into the canon of constructed knowledge. If research methodology answers the questions: "how did this knowledge come into being?" then acknowledging the role of gatekeeping in constructing and obstructing knowledge is critical. Of course, it is risky to write about these concerns prior to works being accepted for publication, but when possible, we should add these notes once our articles have been accepted for publication, or alternatively, find other avenues to publish these reflexive pieces. We are fortunate to live in a moment in history when whiteness is fissured and there are many "varieties of whiteness" (Winant, 1997, p. 40). This means that in my own case there were several white men and women in the academy who reviewed my work, affirmed its value, credibility, and trustworthiness, and permitted it to see the light of day. Making note of these cracks and fissures are equally important for naming our historical moment and interrogating the political economy of knowledge production.

Secondly, it is necessary to find ways in which to maintain an unswerving counterhegemonic presence in critical qualitative research. This does not mean merely presenting a smorgasbord of multiple perspectives in which a counterhegemonic perspective is one of many. Rather, it means exerting our authorial power to saturate the writing not only thick description of context, but also "thick analysis" and a "thick decryption of subtext." This means packing the analysis with questions, standpoints, hard data, case law, and cross-disciplinary research. It means going back in time to narrate the role of history, biography, and intergenerational trauma and its consequences on people of color today. It means locating people within racial hierarchies and holding them accountable for their views. Fine et al. (2003) ask: "Have I connected the "voices" and "stories" of individuals back to the set of historic, structural, and economic relations in which they are situated?" (p. 199). This ethical injunction is appropriate not only for the voices of the oppressed, but the voices of privilege as well. In my book there were many sections in which I wrote about how present day hunger and food insecurity are linked to 
slavery, Native genocide, and Jim Crow. However, what I did not do was probe my white participants about their history of relative privilege. Which of their families got to own farm land and infrastructure because of institutionalized discrimination by the United States Department of Agriculture? Which of their families got to own homes and inherit wealth because of the racist Federal Housing Authority? Which of their families owned slaves? Who participated in the Civil Rights movement and who didn't? My white participants did not bring up their racial histories and it did not occur to me to investigate. However, interpreting Fine's directive from a racial justice imperative means that it is just as important to connect the "voices" and "stories" of Others to historic relations as it to connect the voices of dominant groups. For too long whiteness has escaped social and intellectual surveillance and this is one way thick analysis can be used to reveal long-standing racial imbalances while maintaining a counterhegemonic presence in the research.

Thirdly, as scholars of color, we must constantly remind ourselves that truth is not consensus. This means attending carefully to how consensus and debate are navigated in the analytical and writing process. Geertz (1994) argued that "to commit oneself to a semiotic concept of culture and an interpretive approach to the study of it (sic) is to commit oneself to a view of ethnographic assertion as 'essentially contestable"' (p. 230). Ethnographic assertions are indeed "essentially contestable," but not always in benign ways. In fact feminists like Chandra Talpade Mohanty (1993) warn against the empty pluralism of "harmony in diversity" perspectives that bypass power, history, and struggle (p. 72). As a researcher of color who has received "contests," identifying and naming the source of these disagreements has been crucial to working the Self-Other hyphen. Who contests, who protests, and who concurs? Why does it happen and what kind of pattern does it follow? If we do not recognize these patterns, then we end up feeling like our analysis lacks credibility and we give up. Amid the onslaught of dominant forces, we must be prepared for hegemonic contests from power structures while being clear and honest about our own standpoints and positions. We must be vigilant about the obvious and subtle ways in which white racial frames and white fragility suppress the creation of knowledge. We must be concerned not only with how we treat the voices of people of color and our white participants, but also how we treat our own voices, interpretations, and assertions- our voices that have historically been silenced and continue to be silenced, questioned, dismissed, and suppressed in the academy and elsewhere. This kind of ideological and political transparency in research are necessary for "coming clean" at the Self-Other hyphen. I had a telling moment one semester after all the careful revisions and rewrites on the book were done. One of my students who had earlier identified as politically conservative said: "There are a lot of facts and information presented in the book and a lot of stories, but I still disagree." I smiled because we had now both achieved ideological and political transparency.
In the end, the Self and Other are indeed "knottily entangled" in the research process and troubling these knots is an ongoing process of working the hyphen for all researchers. As an Indian immigrant from the global south, my story is quite different from that of an indigenous woman or a Black man in the United States. There is a vast difference in how we live in the world and how we are received by the world, yet when Xavier leaned back in his chair and said "now I can feel a little comfortable" our worlds joined. I intentionally use the phrase "person of color" to signal my solidarity with Xavier and participants of color and to acknowledge our shared experiences of racism, colonialism, exclusion, microagressions, hypervisibility, and invisibility. As a researcher, I use the tools that I have to join in social struggles with those who have been subjugated because like Xavier I know what it means to be uncomfortable and what it means to feel "at home." I know what it means to be vigilant and what it means to lean back in the chair. I know what it means to have skin that is always suspicious. I cannot write about the Other, because I am the Other. But this entanglement makes navigating the hyphen grueling labor- the labor of writing with "theoretical rigor and political savvy" (Fine et al., 2003, p. 199), the labor of writing with ideological transparency, the labor of writing with passion and compassion, the labor of always remembering the voices and bodies that have been forgotten, the labor of comprehending and responding to white fragility, and the labor of battling hegemonic forces that simply prefer the way things are.

\section{DATA AVAILABILITY STATEMENT}

All datasets analyzed for this study are cited in the manuscript/supplementary files.

\section{ETHICS STATEMENT}

The data presented in the book Feeding the Other: Whiteness, Privilege, and Neoliberal Stigma in Food Pantries (de Souza, 2019) is from the research project titled The Food-Based Community Economy: Understanding How Community Enterprises Provide for Those Experiencing Food Scarcity, a 4-year, mixed methods project examining the various ways in which individuals who experience food insecurity provision themselves. All research protocols were approved by the Institutional Review Board of the University of Minnesota IRB Code Number 1106S01082. Consent was obtained at the individual level for each client, staff member, and volunteer interviewed.

\section{AUTHOR CONTRIBUTIONS}

The author confirms being the sole contributor of this work and has approved it for publication. 


\section{REFERENCES}

Anzaldúa, G. (2015). "Speaking in tongues: a letter to Third World Women writers," in This Bridge Called My Back, 4th Edn, eds C. Moraga and G. Anzaldúa (Albany, NY: SUNY), 163-172.

Bhavnani, K.-K. (1993). Tracing the contours: feminist research and feminist objectivity. Women's Stud. Int. Forum 16, 95-104. doi: 10.1016/0277-5395(93)90001-P

Bonilla-Silva, E. (2010). Racism Without Racists: Color-Blind Racism and the Persistence of Racial Inequality in the United States, 3rd Edn. New York, NY: Rowman and Littlefield.

Carter, R. (1997). "Is white a race? Expressions of white racial identity," in Off White: Readings on Race, Power, and Society, eds M. Fine, L. Weis, L. Powell, and L. M. Wong (New York, NY: Routledge), 198-209.

Chen, V., and Pearce, W. (1995). "Even if a thing of beauty, can a case study be a joy forever? A social constructivist approach to theory and research," in Leeds-Hurwitz, Social Approaches to Communication, ed W. Leeds-Hurwitz (New York, NY: Guilford Press), 135-155.

Collins, P. H. (1990). Black Feminist Thought: Knowledge, Consciousness and the Politics of Empowerment. New York, NY: Routledge.

Cook, D. (1997). "The art of survival in white academia: black women faculty finding where they belong," in Off White: Readings on Race, Power, and Society, eds M. Fine, L. Weis, L. Powell, and L. M. Wong (New York, NY: Routledge), 100-109.

de Souza, R. (2019). Feeding the Other: Whiteness, Privilege, and Neoliberal Stigma in Food Pantries. Cambridge, MA: MIT Press.

Denzin, N., and Lincoln, Y. (2018). "Introduction: the discipline and practice of qualitative research," in Handbook of Qualitative Research, 5th Edn, eds N. Denzin and Y. S. Lincoln (Thousand Oaks, CA: Sage), 31-76.

DiAngelo, R. (2011). White fragility. Int. J. Crit. Pedag. 3, 54-70.

Donnor, J., and Ladson-Billings, G. (2018). "Critical race theory and the postracial imaginary," in Handbook of Qualitative Research, 5th Edn, eds N. Denzin and Y. S. Lincoln (Thousand Oak, CA: Sage), 351-383.

Dutta-Bergman, M., and de Souza, R. (2008). Reconciling the past and present: reflexivity in the critical-cultural approach to health campaigns. Health Commun. 23, 326-339. doi: 10.1080/10410230802229704

Ellingson, L. (2009). Engaging Crystallization in Qualitative Research: An Introduction. Thousand Oaks, CA: Sage Publications.

Feagin, J. (2013). The White Racial Frame: Centuries of Racial Framing and Counter- Framing. New York, NY: Routledge.

Fine, M. (1994). "Working the hyphens: reinventing the self and other in qualitative research," in Handbook of Qualitative Research, eds N. Denzin, and Y. S. Lincoln (Thousand Oak, CA: Sage), 70-82.

Fine, M., Weis, L., Weseen, S., and Wong, L. (2003). "For whom? Qualitative research, representations, and social responsibilities," in The Landscape of Qualitative Research, 2nd Edn, eds N. K. Denzin and Y. S. Lincoln (Thousand Oaks, CA: Sage), 167-207.

Finlay, L. (2002). 'Outing' the researcher: the provenance, process, and practice of reflexivity. Qual. Health Res. 12, 531-545. doi: 10.1177/104973202129120052

Foley, D. (2000). "The politics of studying Raza Unida Politics: reflections of a white anthropologist," in Reflexiones 1999: New Directions in Mexican American Studies, eds R. Flores (Austin, TX: Center for Mexican American Studies, University of Texas), 51-80.

Frankenberg, R. (1993). White Women, Race Matters: The Social Construction of Whiteness. Minneapolis, MN: University of Minnesota.

Frey, L., Pearce, L. W., Barnett, Pollock, M., and Artz, L. (1996). Looking for justice in all the wrong places: on a communication approach to social justice. Commun. Stud. 47, 110-127. doi: 10.1080/10510979609 368467

Geertz, C. (1994). "Thick description: toward an interpretive theory of culture," in Readings in the Philosophy of Social Science, eds M. Martin and L. McIntyre (Cambridge, MA: MIT Press), 213-231.

Gilens, M. (1999). Why Americans Hate Welfare: Race, Media, and the Politics of Antipoverty Policy. Chicago, IL: University of Chicago.

Haraway, D. (1988). Situated knowledges: the science question in feminism and the privilege of partial perspective. Feminist Stud. 14, 575-600. doi: $10.2307 / 3178066$

Hurtado, A., and Stewart, A. (1997). "Through the looking glass: implications of studying whiteness for feminist methods," in Off White: Readings on Race, Power, and Society, eds M. Fine, L. Weis, L. Powell, and L. M. Wong (New York, NY: Routledge), 297-311.

Jones, J., and Norwood, K. J. (2017). Aggressive encounters and white fragility: deconstructing the trope of the angry black woman. Iowa Law Rev. 102, 2017-2069.

Kobayashi, A., and Peake, L. (2000). Racism out of place: thoughts on whiteness and an antiracist geography in the new millennium. Ann. Assoc. Am. Geogr. 90, 392-403. doi: 10.1111/0004-5608.00202

Mohanty, C. T. (1993). Beyond a Dream: Deferred Multicultural Education and the Politics of excellence. Minneapolis, MN: University of Minnesota Press.

Patton, M. (2002). Qualitative Research and Evaluation Methods. Thousand Oaks, CA: Sage.

Rastogi, R., and Dutta, M. (2015). Neoliberalism, agriculture and farmer stories: voices of farmers from the margins of India. J. Creat. Commun. 10, 128-140. doi: $10.1177 / 0973258615597380$

Rosenberg, P. (1997). "Underground discourses: exploring whiteness in teacher education," in Off White: Readings on Race, Power, and Society, eds M. Fine, L. Weis, L. Powell, and L. M. Wong (New York, NY: Routledge), 79-89.

Sastry, S., and Lovari, A. (2017). Communicating the ontological narrative of Ebola: an emerging disease in the time of "Epidemic 2.0". Health Commun. 32, 329-338. doi: 10.1080/10410236.2016.1138380

Slocum, R. (2007). Whiteness, space and alternative food practice. Geoforum 38, 520-533. doi: 10.1016/j.geoforum.2006.10.006

Walley-Jean, J. C. (2009). Debunking the myth of the "Angry Black Woman": an exploration of anger in young African American women. Black Women Gender Fam. 3, 68-86. doi: 10.1353/bwg.0.0011

Wellman, D. (1993). Portraits of White Racism, 2nd Edn. Cambridge University Press.

Winant, H. (1997). "Behind blue eyes: whiteness and contemporary U.S. racial politics," in Off White: Readings on Race, Power, and Society, eds M. Fine, L. Weis, L. Powell, and L. M. Wong (New York, NY: Routledge), 40-53.

Zoller, H., and Dutta, M. (2008). Emerging Perspectives in Health Communication: Meaning, Culture, and Power. New York, NY: Routledge.

Conflict of Interest: The author declares that the research was conducted in the absence of any commercial or financial relationships that could be construed as a potential conflict of interest.

Copyright $\odot 2019$ de Souza. This is an open-access article distributed under the terms of the Creative Commons Attribution License (CC BY). The use, distribution or reproduction in other forums is permitted, provided the original author(s) and the copyright owner(s) are credited and that the original publication in this journal is cited, in accordance with accepted academic practice. No use, distribution or reproduction is permitted which does not comply with these terms. 